\title{
Cervical and breast cancer screening in wheelchair dependent females
}

\author{
A Graham, G Savic and B Gardner \\ National Spinal Injuries Centre, Stoke Mandeville Hospital, Aylesbury, Bucks HP21 8AL, UK
}

\begin{abstract}
The aim of this study was to compare the attendance rates for cervical and breast cancer screening in wheelchair dependent spinal cord injured (SCI) women with those in the general female population in England. The study was conducted as a postal questionnaire survey with an effective response rate of $79 \%$. The attendance rates of the eligible SCI groups were $84 \%$ for cervical screening and $72 \%$ for mammography, both figures being well within the national average attendance rates in the general female population. Difficulties with cervical screening were reported in $58 \%$ and with mammography in $43 \%$ of the cases, including restricted access to clinics, examining rooms and examining couches and positioning during the procedure. These were also the main reasons given for non attendance. The article points out ways to enable even more wheelchair dependent women to benefit from the preventative screening programmes.
\end{abstract}

Keywords: spinal cord injury (SCI); cervical screening; breast screening

\section{Introduction}

Screening uptake among the target female population is the most important factor in the success of the National Health Service (NHS) preventative screening programmes for cervical and breast cancer.

The NHS cervical screening programme recommends assessing women aged $20-64$ every $3-5$ years by taking a cervical smear. The target of the programme is to reduce the incidence of invasive cervical cancer by at least $20 \%$ by the year 2000 . It is estimated that a reduction in mortality between $65 \%$ and $70 \%$ can be expected in the long term, provided that uniform acceptance rates of $80 \%$ are achieved. ${ }^{1}$

The NHS breast screening programme aims to assess women aged 50-64 every 3 years by mammography. The target is to reduce mortality from breast cancer by $25 \%$ in the population of women invited to be screened. ${ }^{2}$ For the programme to be effective, over $70 \%$ of the target population must accept the invitation for screening. ${ }^{3-5}$

We examined the participation of wheelchair dependent spinal cord injured (SCI) women in these programmes.

\section{Methods}

\section{Subjects}

The sample was obtained using the National Spinal Injuries Centre (NSIC) Database. Two hundred and fifty-six consecutive SCI female patients, who fulfilled the study criteria and whose survival status and home

Correspondence: B Gardner address could be confirmed by their GPs, were contacted. The inclusion criteria were that the female was between 20 and 64 years old at the time of the survey and wheelchair dependent (Frankel grade A, B and C) when last seen in the NSIC.

\section{Instrument}

Following ethics committee approval, a 12 item questionnaire (Appendix 1) about cervical screening was sent to the home address of all subjects. The 68 women now aged between 50 and 64 received in addition a two item questionnaire (Appendix 2) about mammography.

\section{Results}

Of the 256 questionnaires sent to the patients, 208 were completed (response rate $81 \%$ ). Six of these were excluded from the study because the patients were functional walkers, leaving 202 questionnaires for analysis (effective response rate $79 \%$ ).

Level of spinal cord injury

Of the 202 patients, 61 were tetraplegics $(30 \%)$ and 141 paraplegics $(70 \%) .109(54 \%)$ were complete (Frankel grade A) and $93(46 \%)$ incomplete (Frankel grade B or C only) injuries (Table 1).

\section{Age}

At the time of injury the age of the patients ranged from $0-58$ years (mean 26). One hundred and nineteen 
were over 20 years old and eligible for cervical screening at that time.

The age of the women at the time of the study ranged from 21-64 years (mean 44), making the entire sample eligible for cervical screening. The 68 women aged between 50 and 64 were also eligible for routine mammography.

Cervical screening before injury

Of the 119 women eligible for cervical screening before their injury, $86(72 \%)$ had been screened. Most screenings were performed either at GP surgeries $(55 \%)$ or at well women/family planning clinics $(35 \%)$

\section{Cervical screening after injury}

One hundred and seventy women (84\%) have been screened since their injury, most of them regularly, either every 3 years $(48 \%)$ or every 5 years $(27 \%)$.

The attendance rate for paraplegics was $87 \%$ and tetraplegics $79 \%$

The attendance breakdown is shown in Table 2 .

Fifty-five percent of those screened had it done at their GP surgeries, $15 \%$ at well women/family planning clinics, $14 \%$ at hospital clinics and $15 \%$ at home (usually arranged by their GPs and performed by practice nurses).

Reported difficulties with cervical screening

Difficulties with obtaining the smear were reported by 98 women $(58 \%$ of those screened).

The most frequently reported difficulties were restricted access to the building $(9 \%)$, restricted access to the examining couch $(17 \%)$ and difficulty with transferring to and from the examining couch $(12 \%)$. Inaccessibility of GP surgeries and in particular well women/family planning clinics was the reason for 26 women $(15 \%)$ arranging for their smears to be taken at home.

Table 1 Level and completeness of injury (No of cases)

\begin{tabular}{lccc}
\hline & Complete & Incomplete & Total \\
\hline Tetra & 22 & 39 & 61 \\
Para & 87 & 54 & 141 \\
Total & 109 & 93 & 202 \\
\hline
\end{tabular}

Table 2 Cervical screening attendance (No of cases)

\begin{tabular}{lccc}
\hline & Screened & Not screened & Total \\
\hline Tetra & 48 & 13 & 61 \\
Para & 122 & 19 & 141 \\
Total & $170(84 \%)$ & $32(16 \%)$ & $202(100 \%)$ \\
\hline
\end{tabular}

Table 3 shows the venue where smears were taken before and after injury.

Thirty-two women (16\% of the sample) did not have their smears taken after injury, even though 15 of them had been screened before injury. In most cases the reasons they stated for not attending were directly related to their disability.

Twenty-three of the 32 said that they would accept the screening if it were available at the NSIC.

\section{Mammography}

Sixty-eight women in the sample were aged over 50 , making them eligible for mammography screening. Fifty-three of these had received an invitation for mammography ( $78 \%$ of the eligible group). Forty-nine attended, which is $92 \%$ of the invited ones, or $72 \%$ of the entire eligible group. Of the four who did not attend, one was a tetraplegic and three were paraplegics.

Twenty-one of the 49 who attended $(43 \%)$ reported difficulties with the screening procedure. The most frequent problems were first gaining access into the building or to the mammography machine and second positioning and balancing in the wheelchair during the procedure.

\section{Discussion}

Table 4 indicates that the attendance rates for cervical screening and mammography in SCI patients and in the

Table 3 Cervical screening venue before and after injury

\begin{tabular}{lcc}
\hline Screening venue & $\begin{array}{c}\text { Before } \\
\text { injury } \\
(\%)\end{array}$ & $\begin{array}{c}\text { After } \\
\text { injury } \\
(\%)\end{array}$ \\
\hline GP surgery & 55 & 55 \\
Well women/family planning clinic & 36 & 15 \\
Hospital clinic & 9 & 14 \\
At home & - & 15 \\
Occupational health clinic & - & 0.6 \\
& & (one) \\
\hline
\end{tabular}

Table 4 Cervical and breast cancer screening attendance rates

\begin{tabular}{|c|c|c|c|c|}
\hline & $\begin{array}{c}\text { Desired } \\
\text { accept- } \\
\text { ance } \\
\text { rates* }\end{array}$ & $\begin{array}{r}\text { Gene } \\
\text { England }\end{array}$ & $\begin{array}{l}\text { ral female } \\
\text { pulation } \\
\text { Oxford } R H A\end{array}$ & $\begin{array}{c}\text { SCI } \\
\text { women }\end{array}$ \\
\hline $\begin{array}{l}\text { Cervical } \\
\text { screening }\end{array}$ & $>80 \%$ & $83 \%$ & $86 \%$ & $84 \%$ \\
\hline Mammography & $>70 \%$ & $72 \%$ & $76 \%$ & $72 \%$ \\
\hline
\end{tabular}


general female population in England are similar. The desired acceptance rates were exceeded for both procedures.

Whilst these overall figures are encouraging, they hide a number of specific problem areas for disabled people.

Firstly, although the cervical screening acceptance rate for the SCI women was $84 \%$ overall, the acceptance rate for the tetraplegic group was only $79 \%$, which is below the desired acceptance rate.

Secondly, 15 of the 86 patients who had been screened before injury were not part of the screening programme following it. The main reasons given by them for not attending were problems with access to well women/family planning clinics and GP surgeries, small examining rooms restricting access to the examining couch and high examining couches with limited hoisting/transfer equipment. Even amongst those patients who continued to be screened access was reported to be a problem in $58 \%$.

The study indicates the resilience and versatility of disabled wheelchair dependent SCI patients. To achieve the screening, many women altered their venue after injury. In particular, $15 \%$ had their smears carried out at home.

It is interesting to note that the theoretical uptake in our group is $95 \%$, as only $5 \%$ of the entire sample did not wish to attend for screening, either in primary care, or at the Spinal Unit. Part of the explanation for this is that SCI patients are educated about general self-care during their first admission so as to avoid complications of their spinal cord injury.

We found the invitation procedure for mammography to be less efficient than for cervical screening, as only $78 \%$ of the women eligible in our study were invited. It is remarkable that $92 \%$ of those invited attended. Many women were prepared to travel to hospitals at some distance because of the inaccessibility of the mobile units to which they were first invited. This uptake is all the more impressive since $43 \%$ of those who attended still reported difficulties with access and positioning during the procedure.
In conclusion, although the attendance rates for cervical screening and mammography in wheelchair dependent SCI females fall within the NHS guidelines, the high success rate owes more to the persistence and effort of the patients than to local factors.

Many difficulties which could be corrected stand in the way of wheelchair dependent SCI women obtaining cervical and breast screening.

Firstly, although it will not be possible to correct current buildings, it is essential that all new buildings, including clinics and mammography machines are wheelchair accessible.

Secondly, hospitals and clinics with established wheelchair access and facilities could be encouraged to set up well women/family planning clinics for wheelchair dependent women.

Thirdly, female wheelchair dependent persons could be informed of those clinics and hospitals in their local area that have wheelchair accessible facilities.

Finally, domiciliary cervical screening could be made more widely available.

\section{Conclusions}

Attendance rates for cervical and breast cancer screening in wheelchair dependent females compared favourably with those in the general female popualtion, in spite of numerous difficulties reported. Many problems could be rectified by relatively simple means in order to enable even more SCI women to benefit from the preventative screening programmes.

\section{References}

1 Austoker J. Cancer prevention in primary care: Screening for cervical cancer. BMJ 1994; 309: 241 - 248.

2 Austoker J. Cancer prevention in primary care: Screening and self examination for breast cancer. BMJ 1994; 309: 168 - 174

3 Blamey RW, Wilson ARM, Patnick J, Dixon MJ. Screening for breast cancer. BMJ 1994; 309: 1076-1079.

4 Department of Health. Health and social services statistics for England 1994 edn. HMSO: London 1994, p 68.

5 Rudiman R, Gilbert FJ, Ritchie LD. Comparison of uptake of breast screening, cervical screening and child immunisation. $B M J$ 1995; 310: $229-230$. 
APPENDIX 1

\section{CERVICAL SCREENING QUESTIONNAIRE}

QUESTION 1 .

WHAT IS YOUR LEVEL OF SPINAL CORD INJURY?

$\begin{array}{ll}\text { CERVICAL } & (\text { ) } \\ \text { THORACIC } & (\text { ) } \\ \text { LUMBAR } & (\text { ) } \\ \text { CAUDA EQUINA } & (\text { ) } \\ \text { UNKNOWN } & (\text { ) }\end{array}$

OUESTION 1 a.

IS YOUR INJURY COMPLETE OR INCOMPLETE?

COMPLETE

INCOMPLETE

UNKNOWN

QUESTION 2 .

WHAT AGE WERE YOU AT THE TIME OF YOUR PARALYSIS?

QUESTION 3 .

WHAT AGE ARE YOU NOW?

QUESTION 4 .

DID YOU HAVE CERVICAL SMEAR TESTING BEFORE YOUR INJURY?

YES ( ) if YES proceed to question 5

NO () if NO proceed to question 7

OUESTION 5 .

HOW OFTEN DID YOU HAVE CERVICAL SCREENING PERFORMED?

EVERY YEAR OR MORE OFTEN

EVERY THREE YEARS

EVERY FIVE YEARS

LESS OFTEN THAN EVERY FIVE YEARS ( )

QUESTION 6 .

WHERE WERE THESE SMEARS TAKEN?

WELI WOMAN/FAMILY PLANNING CLINIC

G.P. SURGERY

HOSPITAL CLINIC

( )

( )

)

(1)


QUESTION 9 .

WHERE WERE THESE SMEARS TAKEN?

You may tick more than one box WELL WOMAN/FAMILY PLANNING CIINIC G.P. SURGERY HOSPITAL CLINIC

$(1)$
()

QUESTION 10.

WERE THERE ANY DIFFICULTIES IN OBTAINING THE SMEAR? eg.: RESTRICTED ACCESS TO BUILDING RESTRICTED ACCESS/TRANSFER TO EXAMINING COUCH ( ) OTHER please explain....................

QUESTION 11 .

IF YOU HAVE NOT HAD A CERVICAL SMEAR TEST PERFORMED SINCE YOUR INJURY, WHY NOT?

YOU HAVE CHOSEN NOT TO ( )

PHYSICALLY IMPOSSIBLE TO OBTAIN ACCESS ( )

OTHER REASON please explain..................

$\ldots \ldots \ldots \ldots \ldots \ldots \ldots \ldots \ldots \ldots$

QUESTION 12 .

WOULD YOU PREFER TO HAVE SCREENING PROCEDURES, SUCH AS A

SMEAR TEST, PERFORMED AS PART OF YOUR ROUTINE SPINAL OUTPATIENT ATTENDANCE?

$\begin{array}{ll}\text { YES } & (1) \\ \text { NO } & (1)\end{array}$

Thank you for your time to complete this questionnaire. If you have any further comments, please attach them below.

APPENDIX 2

\section{MAMMOGRAPHY OUESTIONNAIRE}

(only if age $50-64$ )

QUESTION 1 .

HAVE YOU RECEIVED AN INVITATION TO UNDERGO MAMMOGRAPHIC SCREENING AT YOUR LOCAI BREAST SCREENING CENTRE?

YES ( ) if YES proceed to question 2

No () if No end of questionnaire

QUESTION 2 .

DID YOU HAVE ANY PROBLEMS GETTING ACCESS:

INTO THE BUILDING $\quad(\quad)$

TO THE MAMMOGRAPHY MACHINE? （）

Please comment on any specific problems below. 